\title{
Numerical modeling of stresses and buckling loads of isogrid lattice composite structure cylinders
}

\author{
H. Kanou ${ }^{1}$, S. M. Nabavi ${ }^{2}$, J. E. Jam ${ }^{3} *$ \\ ${ }^{1,2 *}$ Department of Aerospace, MUT, IRAN \\ ${ }^{3}$ Composite Materials and Technology Center, MUT, IRAN \\ "Corresponding Author: e-mail: jejam@mail.com
}

\begin{abstract}
Isogrid composite lattice cylindrical structure with or without skins which consists of a system of $\pm \varphi$ (with respect to the shell axis) helical ribs and circumferential ribs, and has no skins or has skins was studied in a numerical method using ANSYS software, where in this model axial compression and/or pressure loads are applied, to determine the different failure modes which are, failure due to stress exceeds material strength, failure due to local buckling of ribs (crippling), failure due to general buckling of the cylinder and failure due to local buckling skin if the skin is existed. An example was studied to compare the results obtained from the numerical method and other research article.
\end{abstract}

Keywords: FEM, Composite Structures, Isogrid Lattice, Buckling Load

DOI: http://dx.doi.org/10.4314/ijest.v5i1.4

\section{Introduction}

The weight saving is of even greater importance in designing space structures because of the high cost of each kilogram of payload. Composite lattice structures provide a great potential to replace conventional metal structures by offering higher strength to weight ratio. Aircraft fuselage and launch vehicle fuel tanks are some of the many applications of these structures in aerospace and aircraft industries (Kidane, 2002). Typically, Composite Grid Stiffened Structures are fabricated using a continuous fiber, organic composite material. These structures are characterized by a shell structure (or skin) supported by a lattice pattern (or grid) of stiffeners either on the inner, outer or both sides of the shell (Huybrechts et al., 1999).

Cylindrical shells are subjected to any combination of in plane, out of plane and shear loads during application. Due to the geometry of these structures, stress analysis and buckling are the most important failure criteria. Buckling failure mode of a stiffened cylindrical shell can further be subdivided into global buckling, local skin buckling and stiffener crippling. Global buckling is collapse of the whole structure, i.e. collapse of the stiffeners and the shell as one unit. Local skin buckling and stiffeners crippling on the other hand are localized failure modes involving local failure of only the skin in the first case and the stiffener in the second case. A grid stiffened cylinder will fail in any of these failure modes depending on the stiffener configuration, skin thickness, shell winding angle, type of applied load, and so on. Several methods have so far been developed to predict the different buckling loads and mode shapes of stiffened cylinders (Kidane, 2002).

Some solutions was restricted to an isogrid lattice metallic structure which consists of a lattice of intersecting ribs forming an array of equilateral triangles integral with the face sheet. An isogrid structure is characterized by face-sheet thickness, rib thickness, rib depth and height of triangle. Analytical methods, such as that compiled in Isogrid Design Handbook (1973) are available for sizing of the above isogrid parameters for a given geometry, load and material of cylinder. Khalane et al. (2008) analyzed the isogrid structure using the finite element method. The effect of variation of geometrical parameters on stresses, buckling failure and weight of a typical cylindrical section under compression was carried out.

The strength and the failure modes of composite latticed cylindrical and conical shells were investigated by Hou and Gramoll (1997). Two main failure modes, general buckling as a shell and excessive shear stress in the members, under axial compressive 
loads are considered. Taghavian et al. (2008) presented a new approach is presented to identify the stiffness matrix of composite lattice panels based on the superposition method per angle of helical ribs. The major aim of their study was to find out a simple approach in order to compute the general stiffness matrix of panels using appropriate relations and equations of composite mechanics.

Zhang et al. (2008a) designed two novel statically indeterminate planar lattice materials, a new Kagome cell (N-Kagome) and a statically indeterminate square cell (SI-square). Their in-plane mechanical properties, such as stiffness, yielding, buckling and collapse mechanisms were investigated by analytical methods. The analytical stiffness was also verified by means of finite element (FE) simulations. Zhang et al. (2008b) established analytical elastic constitutive relations and failure criterion of planar lattice composites based on the assessment of static equilibrium and deformation relations of the representative unit cell. Finite element simulations are carried out to validate the analytical solutions. To analyze the mechanical behaviors of composite lattice structures with finite sizes and strengthened edges, periodic expansion method was developed by Fan et al. (2009a) to get the corresponding equivalent infinite periodic structures. Finite element method was also adopted to testify the theoretical predictions.

Global buckling load for a generally cross and horizontal grid stiffened composite cylinder was determined in Kidanea et al. (2003) and Wodesenbet et al. (2003). This was accomplished by developing an analytical model for determination of the equivalent stiffness parameters of a grid stiffened composite cylindrical shell. This was performed by taking out a unit cell and smearing the forces and moments due to the stiffeners onto the shell. Making use of the energy method the buckling load was solved for a particular stiffener configuration.

Totaro and Gürdal (2005, 2009) proposed an optimization method for composite lattice shell structures under axially compressive loads. The fully analytical approach provides the minimum mass solution under buckling and strength constraints, irrespective of other possible design limitations, such as, shell stiffness constraints. Sayad (2010) derived the mass equation of composite grid stiffened cylindrical shells and three analytical design equations (the helical ribs strength formula, local buckling formula for helical ribs, general buckling formula for shell) under axial compression. The objective function of optimization is mass function and the optimization constraints are the above analytical design equations. The graphical method is used for optimization of problem.

The buckling strengths and constraint factors of various grids under uniaxial compression and tension were achieved by Fan et al. (2009b). To reveal the local buckling strength of periodic lattice composites analytical method based on the classical beamcolumn theory was applied. The failure behavior of lattice composite hollow structures that have been subjected to an external hydrostatic pressure was presented in Frulloni et al. (2007) using the finite element modeling. Furthermore, the development of an experimental procedure to measure the aforementioned resistance and to test the FEM model is also presented.

In this paper; a finite element model was developed by ANSYS software to give solutions to different failure modes discussed above. A brief description was mentioned in modeling the stiffened structure which consists of the main work, and then the common ideas related to solution process of stress and buckling were taken into account to deduce the objective results. Also in this paper; an example was analyzed and its results were compared with such article results to justify the correctness of this model developed, and providing a good reference can be taken in consideration. In general, such comparison must discus the whole failure modes but the article founded stand for just buckling loads results for a lattice composite cylindrical structure, so the comparison in this paper were described in details to buckling failure mode results, and the stress comparison results were excluded.

\section{Finite element modeling}

A 3-D model was built for an isogrid stiffened composite cylinder with or without skins using ANSYS 9 (2006) finite-elements software. An isogrid lattice composite structure element is presented in Figure 1 showing also the basic geometric parameters of the structure. Lattice structures are usually made in the form of thin-walled cylindrical shells and consist of a system of $\pm \varphi$ (with respect to the shell axis) (Vasiliev et al., 2001). At first, the essential parameters of stiffened cylinder are defined clearly like the length of the cylinder $(L)$, its radius $(R)$, rib width $(b)$, rib thickness $(H)$, number of helical ribs $\left(n_{h}\right)$, number of circumferential ribs $(L)\left(n_{c}\right)$, and helical rib angle $(\varphi)$.

Based on the essential parameters described above, the main constructed operations in the mentioned ANSYS software are used to model in general the two types of ribs which are performed by plotting a helical line and drawing the main helical rib then generating a rib volume by sweeping a constructed area pattern along this helix shape, and by using operations such a reflection and radial copy, all of helical ribs will be obtained. For the circumferential ribs; also one of them is constructed by a volume cylinder and then the other are constructed by copying it. The Figure 2 shows the helical and circumferential ribs constructed. The inner and outer skins were constructed by defining a cylindrical volume, and keeping its outer and inner areas to be overlapped with the ribs model developed, in this case the connectivity of lines and points were retained correctly and the model will be ready for mesh in a correct possess. The Figure 3 illustrates an outer skin model performed. Local cylindrical coordinate systems must be defined for each element and corresponding orthotropic properties aligned properly. 


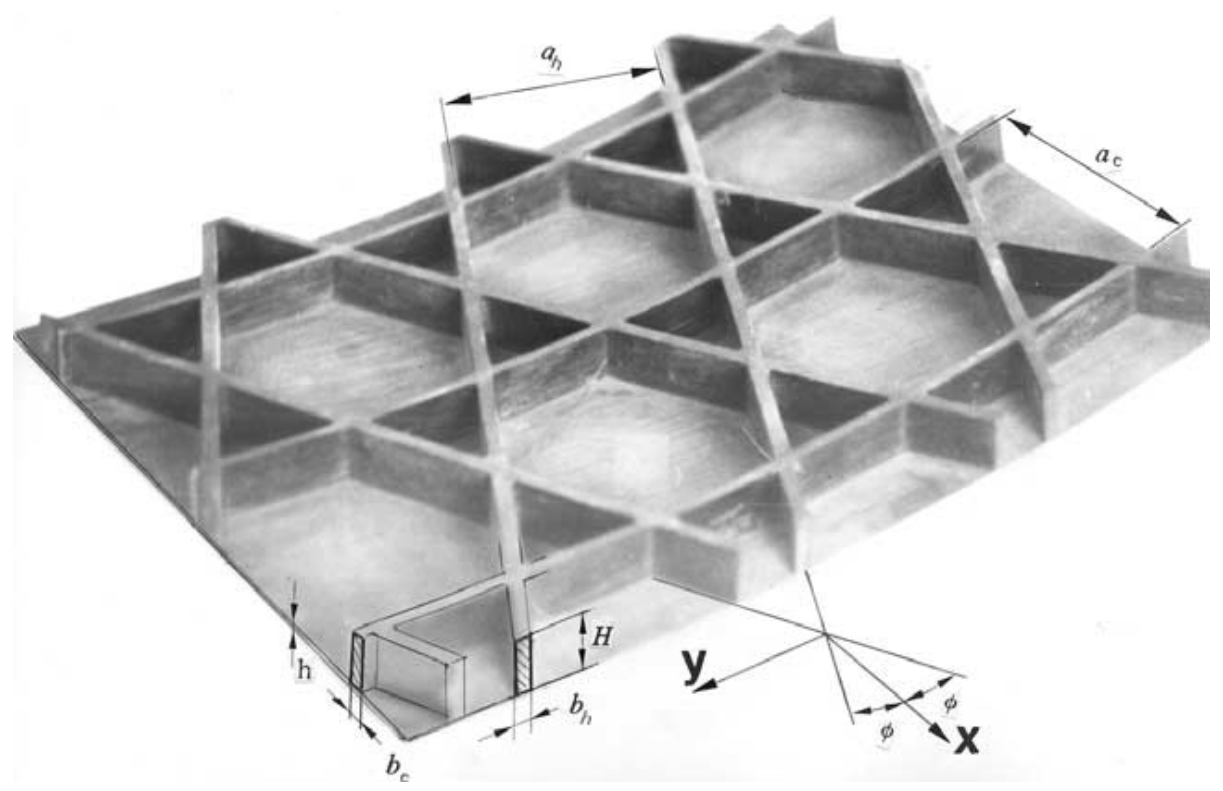

Figure 1. Parameters of a lattice structure (Vasiliev et al., 2001)

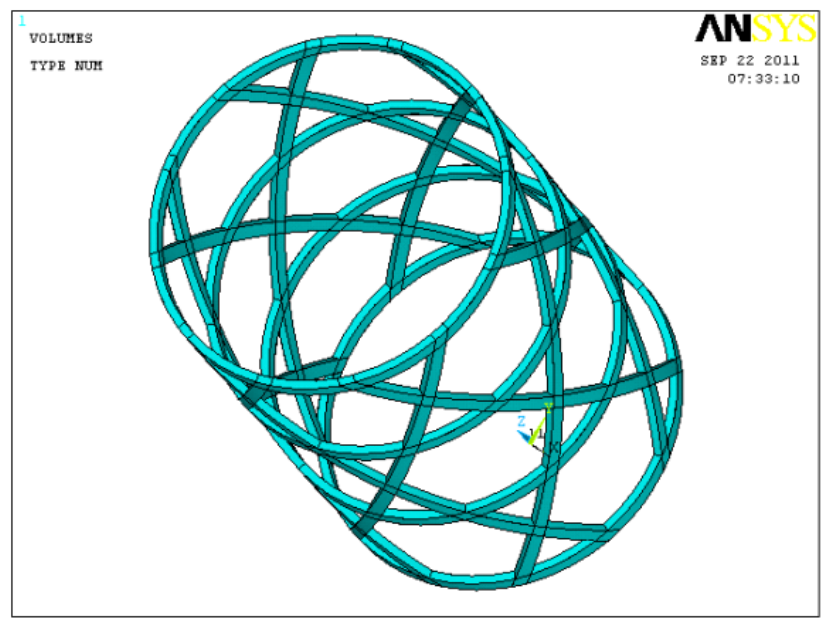

Figure 2. Helical and circumferential ribs constructed

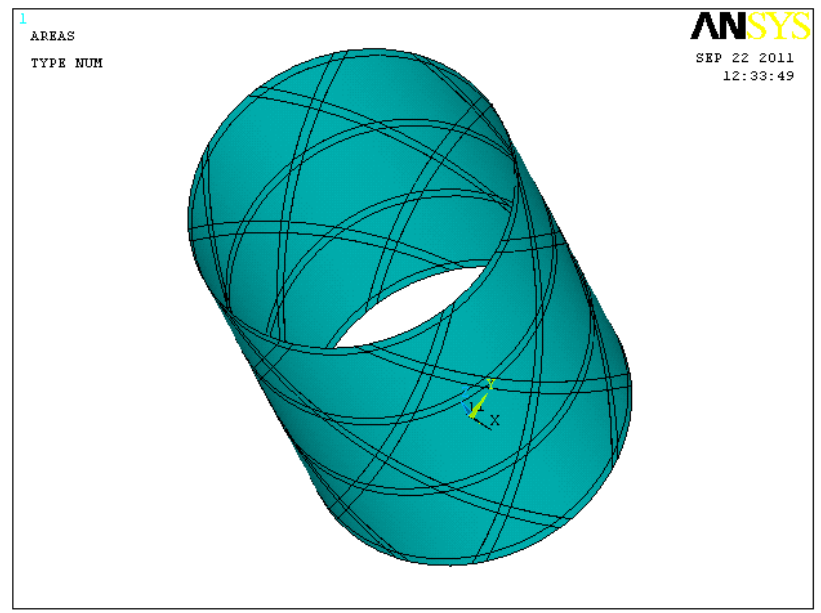

Figure 3. The outer skin 
In this study, the modeling of the stiffeners (ribs) by SOLID191 element type was taken in consideration, where this element has three degrees of freedom per node (translations in the nodal $\mathrm{x}, \mathrm{y}$, and $\mathrm{z}$ directions). Each solid element has a multiple layer in which the orthotropic material properties, layer material direction angles, and layer thickness are defined, so for the ribs which have an angle of $(+\varphi)$, the element used will have this angle in its layer definition, the ribs which have an angle of $(-\varphi)$, the

element used will have this angle in its layer definition, and the circumferential ribs which have an angle of $0^{\circ}$, the element used will have this angle in its layer definition. The modeling of outer or inner skin was done by element type SHELL99, which has six degrees of freedom at each node (translations in the nodal $\mathrm{x}, \mathrm{y}$, and $\mathrm{z}$ directions and rotations about the nodal $\mathrm{x}, \mathrm{y}$, and $\mathrm{z}$-axes), may be used for this layered applications of a structural shell model.

The orthotropic material properties used by the element type are listed under "Material Properties" in the input table for each element type and are input in the program. Orthotropic material properties which are required for an element need nine parameters to be defined $\left(E_{x}, E_{y}, E_{z}, v_{x y}, v_{x z}, v_{y z}, G_{x y}, G_{x z}, G_{y z}\right)$ in general. These parameters must all be input if the element type uses the material property. But these nine parameters can be reduced to five independent parameters in the lattice composite cylinder studied in this thesis in which the relations among the parameters are as follow

$$
E_{y}=E_{z}, \quad v_{x y}=v_{x z}, \quad G_{x y}=G_{x z}, \quad G_{y z}=\frac{E_{y}}{2\left(1+v_{y z}\right)}
$$

So, the parameters can be reduced to five parameters only. By setting the mesh, some factors as the element shape and element size are used in meshing the model. This step is one of the most important of the entire analysis, for the decisions of making the accuracy of the analysis. The size suggested for the element in mesh depend on $\mathrm{H}$ or $\mathrm{b}$ in such case, the size is taken with the lowest one divided by two, in other meaning, if $H<b$ then the element size will be equal to $H / 2$, and if $b<H$ then the element size will be equal to $b / 2$. The Specifying of element shape by setting the allowable element shapes with an element type can take on more than one shape. Area elements can take triangular or quadrilateral shaped in the meshed area, and volume elements can often be either hexahedral (brick) or tetrahedral shaped in the meshed volume, but the configuration of the stiffened cylinder lead to use the quadrilateral shaped in the meshed area and the tetrahedral shaped in the meshed volume for the model, in addition, it gives more accurate solution. The following examples illustrate some meshed models of stiffened cylinder without skins (Figure 4), with inner skin (Figure 5), and with outer skin (Figure 6).

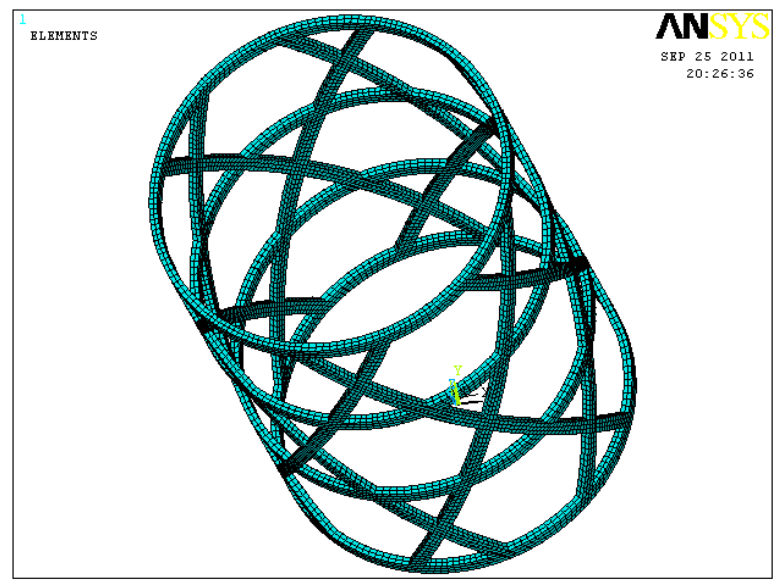

Figure 4. Mesh generation of stiffened cylinder without skins 


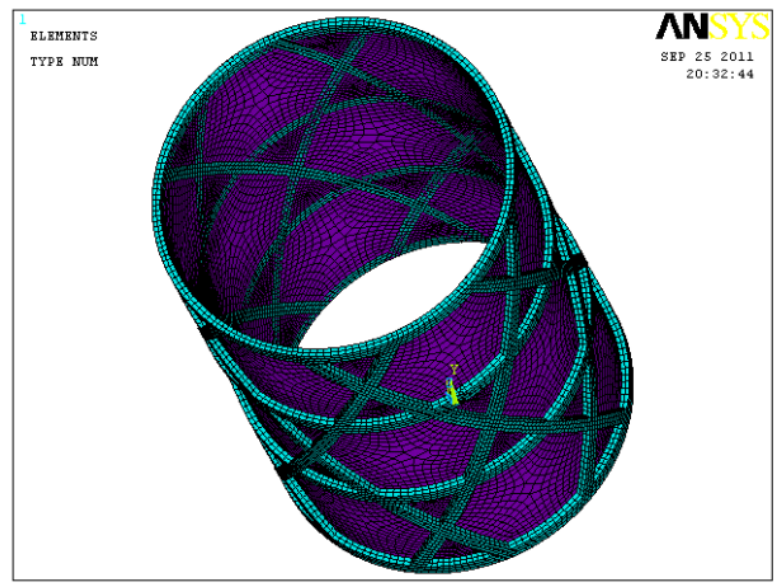

Figure 5. Mesh generation of stiffened cylinder with inner skin

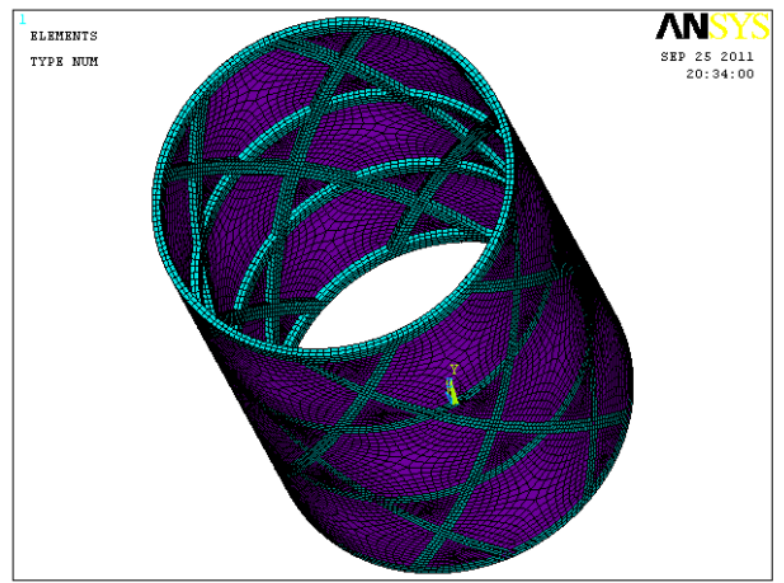

Figure 6. Mesh generation of stiffened cylinder with outer skin

\section{Finite element boundary conditions}

The model studied has is clamped at the bottom of the cylinder and simply supported at its top. The circumferential and radial displacements $v$ and $\omega$ respectively equal to zero at both faces of the cylinder (at $z=0$ and $z=L ; v=\omega=0$ ). Axial displacement $u$ is zero at the bottom face of the cylinder but is non-zero at the top face where the load is applied (at $z=0 ; u=0$ and at $z=L ; u \neq 0$ ).

The loads applied to the studied structure are divided to different cases, which are axial force compression at the top of the cylinder or pressure load in the cylinder, or mixed from the previous loads.

\section{Finite element solution methods}

In this study, the results desired are the stresses and failure buckling modes, which are deduced from the program built in ANSYS as follow. The general study of the stresses in the structures lead to study the diverts components of stresses, but in the stiffened composite cylinder structures, the study will be restricted to just the deducing of the equivalent stresses (von Mises). The equivalent stresses (von Mises) deduced by the static analyses of the structure give us a good estimation of the stress distributions in the structure and show us where the maximum stress is obtained. In this thesis the linear buckling analysis in ANSYS finiteelements software is performed in two steps. In the first step a static solution to the structure is obtained. In this analysis the prebuckling stress of the structure is calculated. The second step involves solving the eigenvalue problem given in the form of equation (1). This equation takes into consideration the prebuckling stress effect matrix $[S]$ calculated in the first step.

$$
\left([K]+\lambda_{i}[S]\right)\{\psi\}_{i}=\{0\}
$$


Where $[K]$ is stiffness matrix, $[S]$ is stress stiffness matrix, $\lambda_{i}$ is the ith Eigen value (used to multiply the loads which generated $[S]$ ) and $\{\psi\}_{i}$ is the ith eigenvector of displacements. The 'Block Lanczos' method in ANSYS was used to extract the eigen values resulting from equation (1). The Eigen values obtained from the buckling analysis are factors by which the initially applied unit force is multiplied. As a result, the critical buckling load is calculated according to equation (2) below.

$$
P_{c r}=\left(\lambda_{i}\right)_{\min } A P
$$

Where, $\left(\lambda_{i}\right)_{\min }$ is the minimum Eigen value, $A$ is the total area on which force is applied, $P$ is the initially applied force. By setting a unit initially applied force $(P=1)$ in equation (2) the critical buckling load will be as follow

$$
P_{c r}=\left(\lambda_{i}\right)_{\min } A
$$

For example for ACL case study (axial compression load) a uniform unit compression force was applied on the upper rim area of the cylinder $(Z=L)$, and by multiplying this area by the Eigen value obtained from the 'Block Lanczos' method in ANSYS, and by the unit force which was applied, the critical buckling load is obtained. The three failure modes for buckling discussed before depend on the parameters of the studied structure.

\section{Obtained finite element results}

After modeling the stiffened cylinder, and deducing the desired solution, the results can obtained easily by choosing the kind of results. At first; for the stress analyzes problem, the equivalent (von Mises) stresses results give the maximum value of the equivalent stresses and the stiffened cylinder can be plotted with the distribution of stresses in it, which can show us the gradient of stresses and the location of the equivalent maximum stress. The following example (Figure 7) illustrates a stiffened cylinder with two load cases applied on it (ACPL (axial compression and pressure loads)).Secondly; For the buckling analyzes problem, the results obtained are the Eigen values obtained from the buckling analysis, and the plotted figures of the stiffened cylinder shows the modes of the buckling such as global buckling, local skin buckling or stiffener crippling in it.

The following three examples (Figure 8, Figure 9, and Figure 10) illustrate the different failure modes in each case, where the cylinder studied with the ACL load case applied on it. In the Figure 8, it is remarked that just in a certain place in the skin, the buckling is obtained, in other meaning; this place has a big distortion comparing with the other skin places. In the Figure 9, the remarked thing is that the entire stiffened cylinder has a distortion like sinusoidal shape. In the Figure 10, it is remarked that just in a certain place in the ribs, the buckling is obtained, in other meaning; this place has a big distortion comparing with the other rib places.

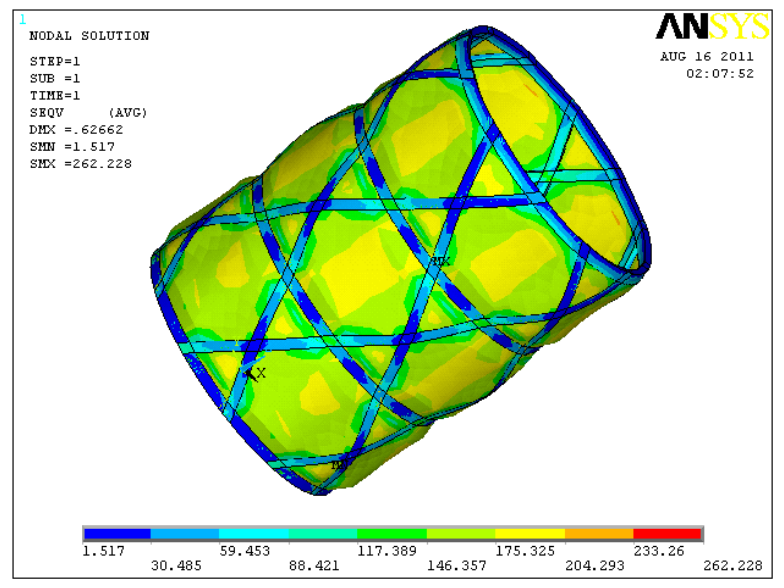

Figure 7. von Mises (equivalent) stress under ACPL 


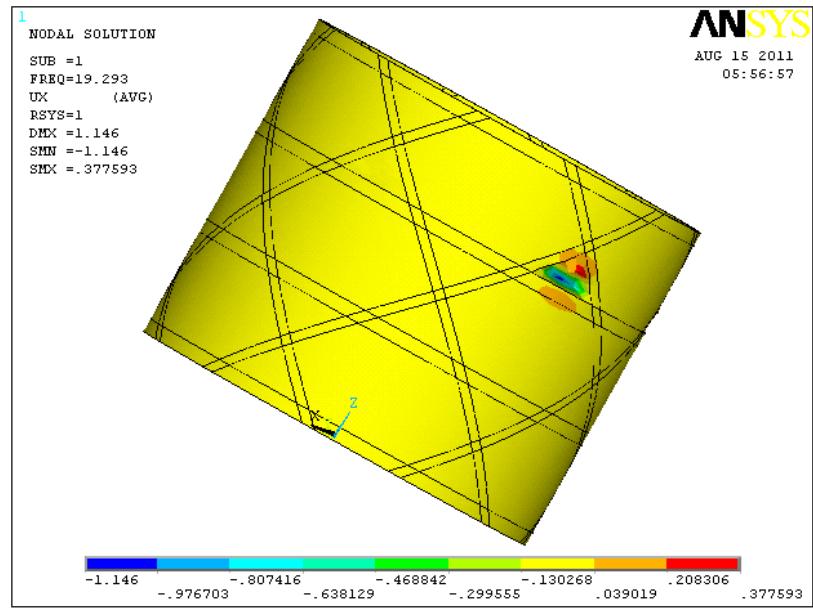

Figure 8. Local skin buckling result example

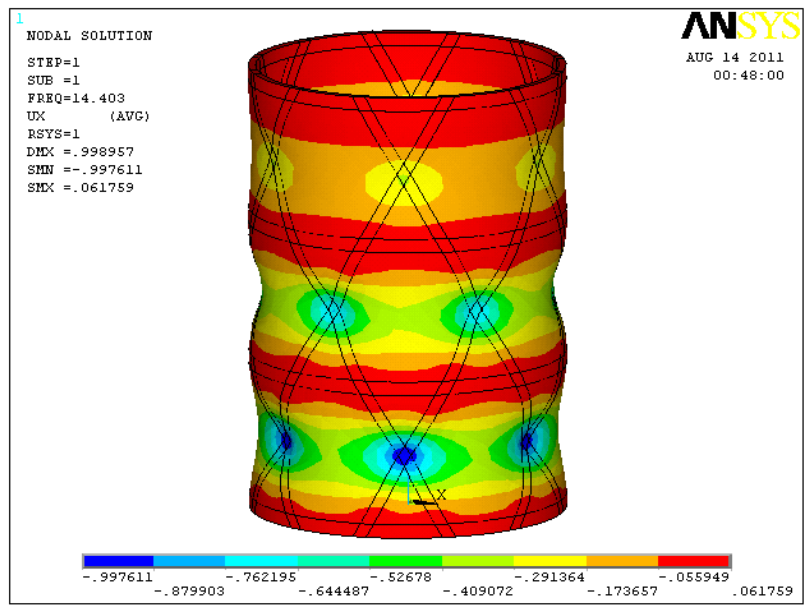

Figure 9. Global buckling result example

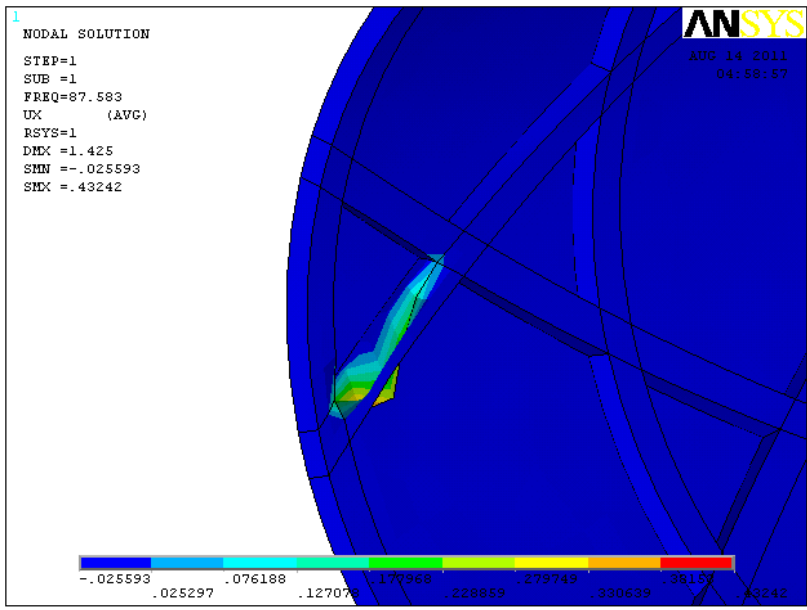

Figure 10. Stiffener crippling result example

\section{Example and comparison and discussion}

In this example studied the parameter values of the stiffened composite cylinder are supposed. The objective of choosing this example is to compare it with the results obtained from a chosen article next and from this comparison; a good estimation of the program developed in ANSYS software will be deduced. 
So this example is closed with matching the parameter values considered in the article. In this example an axial compressive load (ACL) is applied on the stiffened cylinder with outer skin. The parameters of the stiffened cylinder studied are as follow $L=204 \mathrm{~mm}, R=70 \mathrm{~mm}, b=6 \mathrm{~mm}, a_{c}=68 \mathrm{~mm}, \varphi=\pi / 2$. For complete definition of the volume elements, the properties of this element were defined as the number of layer which is one, the layer thickness which is $\mathrm{H}$, layer material directional angles which were the same rib angles and the orthotropic material carbon/epoxy properties used are provided for the ribs as follow:

$$
E_{x}=44.2 \mathrm{Gpa}, \quad E_{y}=E_{z}=5 \mathrm{Gpa}, \quad v_{x y}=v_{x z}=0.194, \quad v_{y z}=0.173, \quad G_{x y}=G_{x z}=4.9 \mathrm{GPa}, \quad G_{y z}=\frac{E_{y}}{2\left(1+v_{y z}\right)}=2.94 \mathrm{GPa}
$$

The skin was modeled with layered composite material which has the following properties:

$$
E_{x}=83.3 \mathrm{Gpa}, \quad E_{y}=E_{z}=6.9 \mathrm{Gpa}, \quad v_{x y}=v_{x z}=0.289, \quad v_{y z}=0.173, \quad G_{x y}=G_{x z}=4.9 \mathrm{GPa}, \quad G_{y z}=\frac{E_{y}}{2\left(1+v_{y z}\right)}=2.94 \mathrm{GPa}
$$

The element skin construction has a ply sequence considered for the skin which is $\left[90^{\circ} /+45^{\circ} /-45^{\circ} / 0^{\circ}\right]_{s}$, and each of them has a 0.1 thickness. The following parameters are supposed for this study in which; $R_{2}$ is the outer radius of the cylinder, $R_{1}$ is the inner radius of the cylinder, $D$ is the inner diameter of the cylinder, $t$ is the skin thickness, and $A$ is the upper circumferential area of the cylinder. The followed relations were derived

$$
\begin{gathered}
R_{1}=\frac{D}{2}, \quad R_{2}=\frac{D}{2}+H+t \\
A=\pi R_{2}^{2}-\pi R_{1}^{2}=\pi\left(R_{2}-R_{1}\right)\left(R_{2}+R_{1}\right)=\pi(H+t)(H+D+t)
\end{gathered}
$$

By substituting the diameter value $(D=2 R=140 \mathrm{~mm})$ in equation (7), the followed area relation is obtained

$$
A=\pi(H+t)(H+140+t)
$$

As mentioned before the equivalent (vonMises) stresses give a good estimation of the stress failure criteria of the structure, and in this study; four cases study were mentioned and clarified in (Figure 11, Figure 12, Figure 13 and Figure 14) which have the same arrangement of Table 1.

Table 1. Such cases study

\begin{tabular}{|c|c|c|c|c|c|}
\hline \multirow{2}{*}{ Case study } & \multicolumn{2}{|c|}{$\begin{array}{c}\text { Parameter values } \\
(\mathrm{mm})\end{array}$} & $\begin{array}{c}\text { Force load applied } \\
F_{s}(\mathrm{KN})\end{array}$ & $\begin{array}{c}\text { Mentioned area } \\
\mathrm{A}\left(\mathrm{mm}^{2}\right)\end{array}$ & $\begin{array}{c}\text { Axial pressure applied } \\
\sigma_{s}=\frac{F_{s}}{A}(\mathrm{MPa})\end{array}$ \\
\cline { 2 - 3 } & $t$ & $H$ & 25 & 1440 & 17.2 \\
\hline 1 & 0 & 3.2 & 31 & 1810 & 17.1 \\
\hline 2 & 0 & 4 & 37 & 2184 & 17 \\
\hline 3 & 0 & 4.8 & 24.7 & 1532 & 16.1 \\
\hline 4 & 0.2 & 3.2 & 25 & 1817 & 13.6 \\
\hline 5 & 0.8 & 3.2 & & & \\
\hline
\end{tabular}

The remarkable thing is that decrease in rib thickness or in skin thickness gives a corresponding increase in equivalent stress von Mises values. This increase was acceptable in this structure where the material volumes were decreased. The stress results obtained illustrate that; the radial, radial-circumferential shear and radial-axial shear stresses are approximately neglected by comparing with other divert stress components.

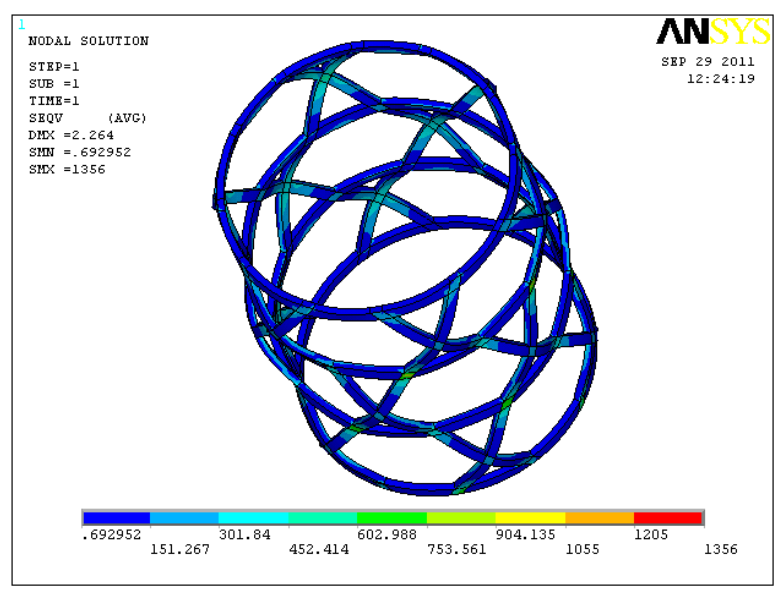

Figure 11. Equivalent (von Mises) stress distributions (first case study) 


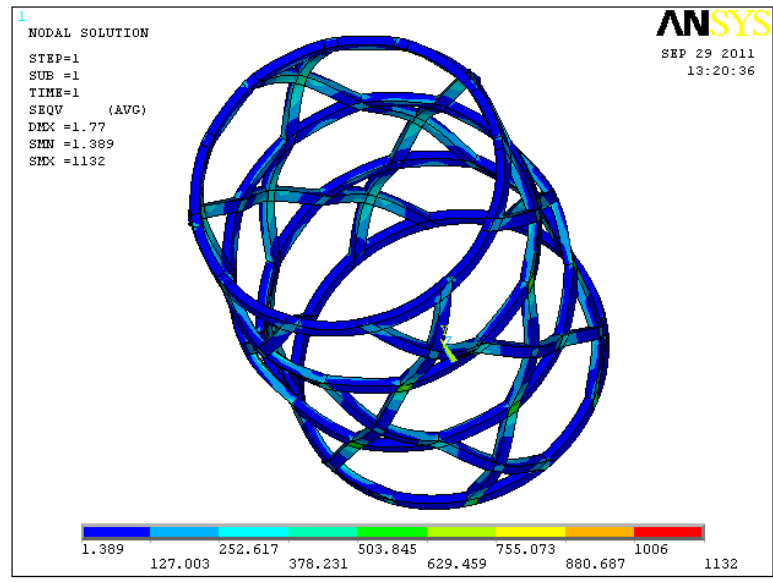

Figure 12. Equivalent (von Mises) stress distributions (second case study)

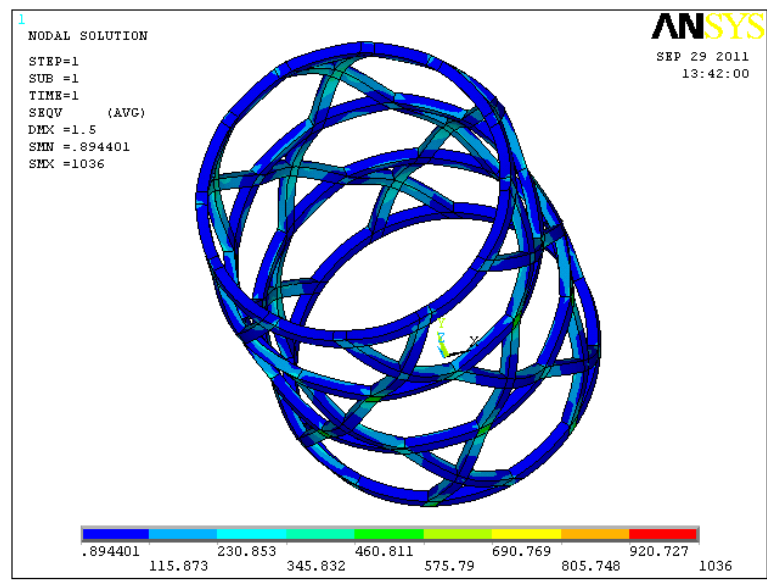

Figure 13. Equivalent (von Mises) stress distributions (third case study)

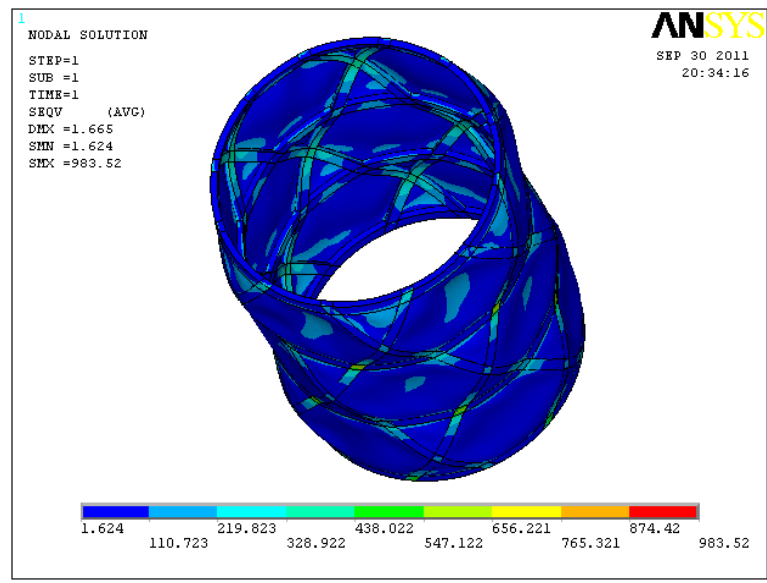

Figure 14. Equivalent (Von Mises) stress distributions (fifth case study)

The main echo studied in this example was the buckling analyses. Their results obtained were compared next with such article results The typical buckled shapes for this stiffened cylinder with outer skin by finite element modeling are given as follows. The first three following selected case study parameters in Table 1 which are mentioned for the study of the stiffened cylinder without skin $(t=0)$ give a global buckling result in each one of them. And then, in the fourth and fifth selected cases study parameters in Table 1 which are mentioned for the study of the stiffened cylinder with outer skin $(t \neq 0)$ give a local buckling skin. The buckling 
results were listed in Table 2 where each minimum Eigen value were tacked from the obtained figures deduced (Figure 15 to 18) and in it the relation (3) were used to determine the critical buckled load.

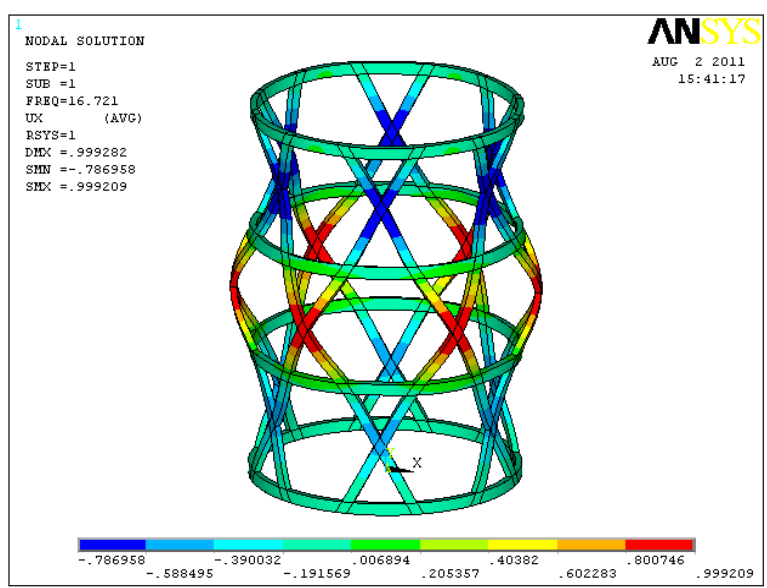

Figure 15. Buckling results $(t=0, H=3.2 \mathrm{~mm})$ for axial load

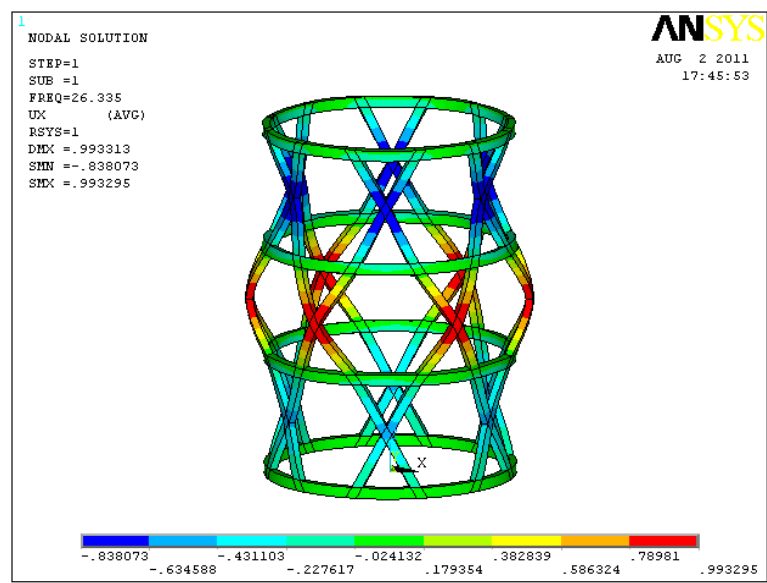

Figure 16. Buckling results $(t=0, H=4 \mathrm{~mm})$ for axial load

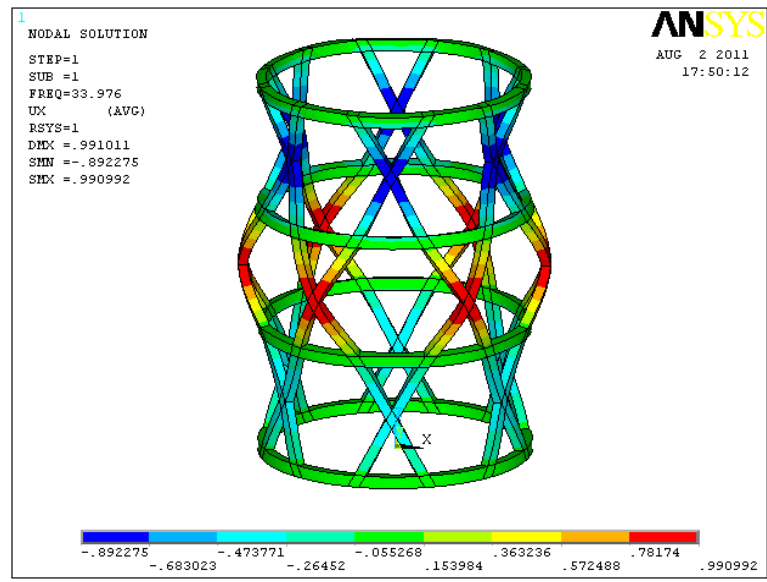

Figure 17. Buckling results $(t=0, H=4.8 \mathrm{~mm})$ for axial load 


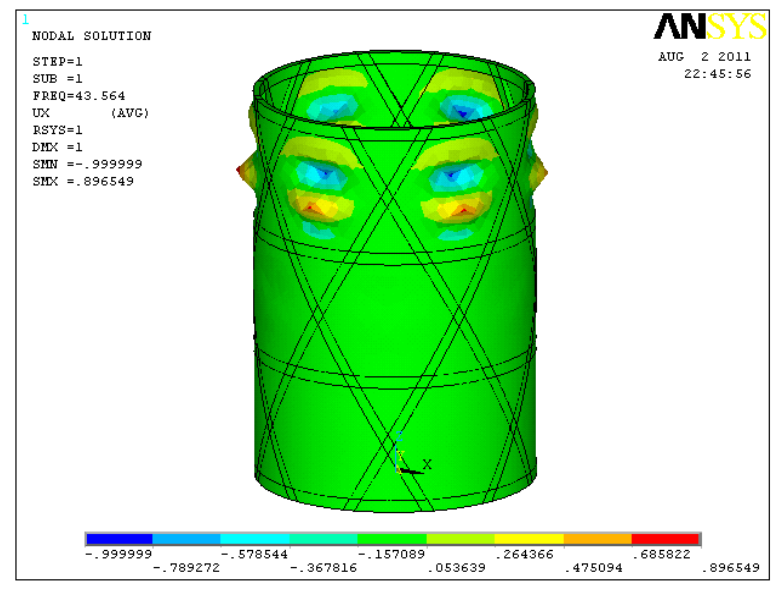

Figure 18. Buckling results $(t=0.8, H=3.2 \mathrm{~mm}$ ) for axial load

Table 2. Buckling ANSYS results

\begin{tabular}{|c|c|c|c|c|c|}
\hline \multirow{2}{*}{ Case study } & \multicolumn{2}{|c|}{$\begin{array}{c}\text { Parameter values } \\
(\mathrm{mm})\end{array}$} & $\begin{array}{c}\text { Minimum Eigen value } \\
\left(\lambda_{i}\right)_{\min }\end{array}$ & $\begin{array}{c}\text { Mentioned area } \\
A\left(\mathrm{~mm}^{2}\right)\end{array}$ & $\begin{array}{c}\text { Critical buckling load } \\
P_{c r}(K N)\end{array}$ \\
\cline { 2 - 3 } & $t$ & $H$ & 16.721 & 1440 & 24.1 \\
\hline 1 & 0 & 3.2 & 26.335 & 1810 & 47.7 \\
\hline 2 & 0 & 4 & 33.976 & 2184 & 74.2 \\
\hline 3 & 0 & 4.8 & 35.494 & 1532 & 54.4 \\
\hline 4 & 0.2 & 3.2 & 43.564 & 1817 & 79.2 \\
\hline 5 & 0.8 & 3.2 & & & \\
\hline
\end{tabular}

It is remarked that the increase in rib thickness or in skin thickness gives increase in critical buckling load values and this increase was acceptable where the structure was stiffer. Also, the local skin buckling is obtained in the upper section of the stiffened cylinder. As the skin thickness is increased the buckling failure mode of the stiffened cylinder is changed from global skin buckling to local buckling and then to stiffener crippling. It is observed that the buckling resistance of the stiffened cylinder increases with increase in skin thickness and this is reasonable where the structure gets stiffer when the skin thickness is increased, and the stress decreases with increase in skin thickness. The example chosen has the same data values described in the article by Buragohain and Velmurugan (2011) which has the buckling results showed in Table 3 and Figure 19.

Table 3. Buckling ANSYS article results (Buragohain and Velmurugan, 2011)

\begin{tabular}{|c|c|c|c|}
\hline \multirow{2}{*}{ Case study } & \multicolumn{2}{|c|}{$\begin{array}{c}\text { Parameter values } \\
(\mathrm{mm})\end{array}$} & $\begin{array}{c}\text { Critical buckling load } \\
P_{c r}(\mathrm{KN})\end{array}$ \\
\cline { 2 - 3 } & $t$ & $H$ & 30.2 \\
\hline 1 & 0 & 3.2 & 50.9 \\
\hline 2 & 0 & 4 & 78.6 \\
\hline 3 & 0 & 4.8 & 66.0 \\
\hline 5 & 0.8 & 3.2 & \\
\hline
\end{tabular}




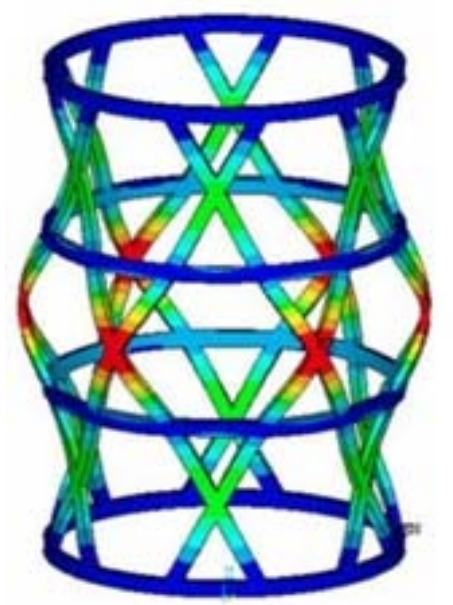

(a)

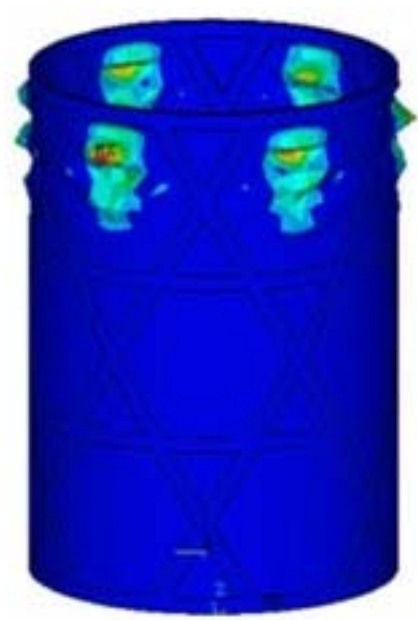

(b)

Figure 19. Typical buckled shapes by finite element modeling

(a) lattice cylinder (b) grid-stiffened shell (Buragohain and Velmurugan, 2011)

The results in the example discussed are listed with the article results in Table 4.

Numerical difference error (\%) $=[$ (Critical buckling load of article-Critical buckling load)/Critical buckling load of article $]$ x 100

Table 4. Buckling ANSYS results comparison

\begin{tabular}{|c|c|c|c|c|c|}
\hline \multirow{2}{*}{ Case study } & \multicolumn{2}{|c|}{$\begin{array}{c}\text { Parameter values } \\
(\mathrm{mm})\end{array}$} & $\begin{array}{c}\text { Critical buckling load } \\
P_{c r}(\mathrm{KN})\end{array}$ & $\begin{array}{c}\text { Critical buckling load } \\
\text { (Buragohain and } \\
\text { Velmurugan, 2011) }\end{array}$ & $\begin{array}{c}\text { Numerical difference } \\
\text { error (\%) }\end{array}$ \\
\cline { 2 - 3 } & $t$ & $H$ & 24.1 & 30.2 & 20.2 \\
\hline 1 & 0 & 3.2 & 47.7 & 50.9 & 6.3 \\
\hline 2 & 0 & 4 & 74.2 & 78.6 & 5.6 \\
\hline 3 & 0 & 4.8 & 79.2 & 66.0 & 20 \\
\hline 5 & 0.8 & 3.2 & & \\
\hline
\end{tabular}

The figure obtained from the mentioned article (Figure 19) has approximately the same buckled shape deduced for this case as in figures obtained by using the ANSYS program developed. This shows us that this numerical model developed is approximately correct. From Table 4 and the results of the article mentioned above shows the correct answers; the remarkable thing is that the numerical difference error decreased with increase in the rib thickness, so we can deduce that the models developed approximately give good results for the models which have a big rib thickness.

\section{Conclusions}

The problem studied in this article was concerned basically with developing a numerical model using the ANSYS software to find the stress and buckling loads in the isogrid lattice composite cylindrical structures with or without skins subjected to axial compression and/or pressure loads. The results showed that the increase in rib thickness or in skin thickness gives a corresponding increase in critical buckling load. Another interesting thing is that the buckling failure mode of the stiffened cylinder is changed from global skin buckling to local buckling and then to stiffener crippling by increasing the skin thickness. The results obtained by the numerical model developed were compared with the results existed in the above mentioned article and good model were greeted from the numerical difference error deduced, so the depending on this numerical model developed by ANSYS software for this problem studied is accepted.

\section{References}

ANSYS Release 9, 2006. ANSYS, Inc, Canonsburg, PA.

Buragohain M., Velmurugan R., 2011. Study of filament wound grid-stiffened composite cylindrical structures, Composite Structures, Vol. 93, No. 2, pp. 1031-1038.

Fan H., Jin F. and Fang D., 2009a. Characterization of edge effects of composite lattice structures, Composites Science and Technology, Vol. 69, pp. 1896-1903.

Fan H., Jin F. and Fang D., 2009b. Uniaxial local buckling strength of periodic lattice composites, Materials and Design, Vol. 30, pp. 4136-4145. 
Frulloni E., Kenny J.M., Conti P. and Torre L., 2007. Experimental study and finite element analysis of the elastic instability of composite lattice structures for aeronautic applications, Composite Structures, Vol. 78, pp. 519-528.

Hou A., Gramoll K., 1997. Strength of composite lattice structures, AIAA-97-1251, Vol. 58-06, Section B, pp. 2510-2520, American Institute of Aeronautics and Astronautics.

Huybrechts S.M., Hahn S.E. and Meink T.E., 1999. Grid stiffened structures: a survey of fabrication, analysis and design methods, Proceedings of the $12^{\text {th }} I E C H$.

Isogrid Design Handbook, 1973, NASA CR-124075, Revision A.

Khalane S.A., Babu J., Kumar A. and Gupta R.K., 2008. Isogrid design aspects for cylindrical shell, Proceedings of the International Conference on Aerospace Science and Technology, 26-28 June, Bangalore, India.

Kidane S., 2002. Buckling analysis of grid stiffened composite structures, Master of Science thesis, Agricultural and Mechanical College, Louisiana State University.

Kidanea S., Lia G., Helmsa J., Panga S. and Woldesenbet E., 2003. Buckling load analysis of grid stiffened composite cylinders, Composites: Part B, Vol. 34, pp. 1-9.

Sayad K., 2010. Optimization for minimum mass of composite grid stiffened cylindrical shells under axial compressive load based on analytical and graphical methods, The $2^{\text {nd }}$ International Conference on Composites: Characterization, Fabrication and Application (CCFA-2), Dec. 27-30, Kish Island, Iran.

Taghavian S.H., Jam J.E. and Nia N.G., 2008. A new approach to identify the stiffness matrix of a composite lattice structures, Association of Metallurgical Engineers of Serbia, UDC: 620.186.183:669-179=20, Scientific paper.

Totaro G., Gürdal Z., 2009. Optimal design of composite lattice shell structures for aerospace applications, Aerospace Science and Technology, Vol. 13, pp. 157-164.

Totaro G., Gürdal Z., 2005. Optimal design of composite lattice structures for aerospace application, European Conference for Aerospace Sciences (EUCASS).

Vasiliev V.V., Barynin V.A. and Rasin A.F., 2001. Anisogrid lattice structures - survey of development and application, Composite Structures, Vol. 54, pp.361-370.

Wodesenbet E., Kidane S. and Pang S., 2003. Optimization for buckling loads of grid stiffened composite panels, Composite Structures, Vol. 60, pp. 159-169.

Zhang Y.H., Qiu X.M. and Fang D.N., 2008a. Mechanical properties of two novel planar lattice structures, International Journal of Solids and Structures, Vol. 45, pp. 3751-3768.

Zhang Y., Fan H., Fang D., 2008b. Constitutive relations and failure criterion of planar lattice composites, Composites Science and Technology, Vol. 68, pp. 3299-3304.

\section{Biographical notes}

H. Kanou received Engineering diploma in Mecatronics from Height Institute of Science and Technology, Syria in 2000. He is an engineer in the center of Research and Technology, Syria.

S. M. Nabavi is with the Department of Aerospace, MUT, IRAN,

J. E. Jam is with the Composite Materials and Technology Center, MUT, IRAN

Received May 2012

Accepted August 2012

Final acceptance in revised form October 2012 